Original Article

\title{
Stability Test of Gel Hand Sanitizer Ethanol Extract of Nutmeg (Pala) Leaves (Myristica fragrans Houtt.) with Variation of the Concentration of HPMC (Hydroxy Propyl Methyl Cellulose) and Glycerine
}

\author{
SRN Endah*, C Shintia, A Nofriyaldi \\ Department of Pharmacy, Universitas Perjuangan Tasikmalaya, Tasikmalaya, Indonesia \\ *Corresponding author: Sri Rezeki Nur Endah I Email: srierezekine@gmail.com
}

Received: 05 January 2021; Revised: 10 February 2021; Accepted: 18 March 2021; Published: 20 March 2021

\begin{abstract}
Nutmeg leaves (Myristica fragrans Houtt.) Have secondary metabolite compounds such as flavonoids, saponins and tannins. Therefore, nutmeg is developed into a hand sanitizer gel dosage form that has the potential to be antibacterial. In gel formulations, the use of gelling agents and humectants is an important factor that can produce a stable gel preparation. The purpose of this study was to determine the stability of the hand sanitizer gel preparation of the ethanol extract of nutmeg leaves with various concentrations of HPMC and glycerin. This hand sanitizer gel is made of 3 formulations with variations of HPMC and glycerin, namely formula 1 (HPMC 1\%: glycerin 5\%), formula 2 (HPMC 1.5\%: glycerin 7.5\%), formula 3 (HPMC 2\%, glycerin $10 \%$ ). The stability test was carried out on the preparation using the cycling test method for 6 cycles.
\end{abstract}

Keywords: Stability; Nutmeg leaf ethanol extract; Hand sanitizer; HPMC; Glycerin

\section{PENDAHULUAN}

Perkembangan zaman menyebabkan produk pembersih tangan dirancang dengan berbagai jenis, mulai dari sabun yang dicuci dengan air hingga produk hand sanitizer dengan kandungan antiseptik yang tidak memerlukan pencucian dengan air [1]. Hand sanitizer banyak digunakan karena alasan kepraktisan penggunaan, mudah dibawa dan bisa cepat digunakan tanpa perlu menggunakan air, selain itu menurut US FDA (Food and Drug Administration) dapat membunuh kuman dalam waktu relatif cepat [2]. Salah satu tanaman yang telah diteliti memiliki aktivitas antibakteri adalah pala (Myristica fragrans Houtt.). Selain itu daun pala memiliki efek farmakologi mengobati diare, muntaber, dan kudis. Dengan kandungan senyawa metabolit sekunder diantaranya saponin, polifenol, flavonoid dan minyak atsiri [3].

Berdasarkan penelitian sebelumnya, ekstrak etanol daun pala dapat menghambat pertumbuhan bakteri Staphylococcus aureus dan bakteri Escherichia coli [4]. Sedangkan sediaan gel hand sanitizer minyak atsiri pala (Myristica fragrans Houtt.) pada konsentrasi 25\% menghasilkan diameter zona hambat terhadap bakteri Staphylococcus aureus sebesar $13.5 \mathrm{~mm}$ [5].Sediaan yang dipilih untuk produk hand sanitizer ini adalah gel. Keuntungan dari sediaan gel adalah tidak lengket, mudah diaplikasikan, tidak meninggalkan lapisan minyak pada kulit [6]. Pada formulasi gel, gelling agent dan humektan merupakan faktor penting yang mempengaruhi kualitas dan stabilitas gel. Kombinasi 
gelling agent dan humektan yang tepat akan menghasilkan gel yang baik dan stabil dalam penyimpanan jangka panjang [7].

HPMC merupakan gelling agent yang sering digunakan karena memiliki kestabilan fisik paling optimal pada sediaan gel serta memiliki ketoksikan yang rendah [8]. Selain itu, HPMC juga memiliki kelebihan diantaranya menghasilkan daya sebar pada kulit yang baik, efeknya mendinginkan, tidak menyumbat pori-pori kulit, dan pelepasan obatnya baik [9]. Penggunaan gliserin sebagai humektan bertujuan untuk dapat mempertahankan air pada sediaan sehingga dapat menjaga kelembapan kulit [10]. Penggunaan jenis dan konsentrasi bahan tambahan yang berbeda akan mempengaruhi kestabilan fisik suatu sediaan sehingga uji stabilitas fisik terhadap sediaan gel hand sanitizer ekstrak etanol daun pala perlu dilakukan. Uji stabilitas fisik dilakukan untuk menjamin sediaan memiliki sifat yang sama setelah sediaan dibuat dan masih memenuhi parameter kriteria selama penyimpanan [11]. Untuk memperoleh nilai kestabilan suatu sediaan, maka dapat dilakukan uji stabilitas dengan metode cycling test, sediaan disimpan pada suhu $4^{\circ} \mathrm{C}$ selama 24 jam, kemudian dipindahkan ke dalam oven yang bersuhu $40^{\circ} \mathrm{C}$ selama 24 jam (satu siklus). Uji ini dilakukan sebanyak 6 siklus atau selama 12 hari [12].

Berdasarkan uraian diatas, maka dilakukan penelitian mengenai uji stabilitas sediaan gel hand sanitizer ekstrak etanol daun pala (Myristica fragrans Houtt.) dengan variasi konsentrasi HPMC dan gliserin.

\section{BAHAN DAN METODE}

\subsection{Alat}

Maserator, rotary evaporator, cawan uap, mortir dan stamper, timbangan analitik, batang pengaduk, pH meter, oven, water bath, hot plate, blender dan alat-alat laboratorium lainnya.

\subsection{Bahan}

Daun pala, HPMC (Hidroxy Propyl Methyl Cellulose), gliserin, propilenglikol, Trietanolamin (TEA), methylparaben, etanol 96\%, NaOH, $\mathrm{FeCl} \neg 3, \mathrm{HCl}, \mathrm{H} 2 \mathrm{SO} 4$, larutan gelatin 1\%, amil alkohol, serbuk magnesium, dan pereaksi Lieberman-Burchard.

\subsection{Persiapan Bahan dan Ekstraksi}

Sampel yang digunakan dalam penelitian ini adalah daun pala yang diperoleh dari Kp. Banuherang Desa Banyuresmi Kecamatan Sukahening Kabupaten Tasikmalaya. Daun pala yang diperoleh kemudian dibersihkan dengan air mengalir untuk menghilangkan kotoran-kotoran yang melekat pada daun, kemudian dilakukan perajangan dan dikeringkan menggunakan oven pada suhu $\pm 50^{\circ} \mathrm{C}$. Simplisia dihaluskan dengan cara diblender sehingga diperoleh serbuk simplisia, kemudian serbuk simplisia disimpan dalam wadah yang kering tertutup rapat.

Serbuk simplisia daun pala diekstraksi dengan metode maserasi menggunakan pelarut etanol 96\%. Maserasi dilakukan selama 3 hari dengan pergantian pelarut setiap 24 jam sekali, kemudian maserat disaring dan dipekatkan menggunakan rotary evaporator sampai dihasilkan ekstrak kental. 
2.4. Formula

Tabel 1. Formula Gel Hand Sanitizer ekstrak etanol daun pala

\begin{tabular}{ccccc}
\hline & \multicolumn{4}{c}{ Konsetrasi (\%) } \\
\cline { 2 - 5 } Komposisi & Fungsi & F1 & F2 & F3 \\
\hline Ekstrak daun & Zat aktif & 0.6 & 0.6 & 0.6 \\
pala & & & & \\
HPMC & Gelling agent & 1 & 1.5 & 2 \\
Gliserin & Humektan & 5 & 7.5 & 10 \\
Propilenglikol & Humektan & 10 & 10 & 10 \\
Metilparaben & Pengawet & 0.3 & 0.3 & 0.3 \\
TEA & pengemulsi & 1 & 1 & 1 \\
Aquades ad & Pelarut & 100 & 100 & 100 \\
\hline
\end{tabular}

\subsection{Pembuatan Gel Hand Sanitizer}

HPMC (Hydroxy Propyl Methyl Cellulose) ditaburkan dalam aquades sampai mengembang kemudian ditambahkan gliserin gerus homogen, selanjutnya timbahkan metilparaben yang telah dilarutkan terlebih dahulu dalam propilenglikol kemudian digerus sampai terbentuk massa yang homogen. Selanjutnya ditambahkan sedikit demi sedikit TEA, digerus sampai terbentuk masa gel yang homogen dan tambahkan sisa aquades dengan cara terus dilakukan penggerusan, kemudian ditambahkan zat aktif ekstrak daun pala yang telah dilarutkan terlebih dahulu dalam propilen glikol kemudian digerus hingga terbentuk gel. Gel yang dihasilkan dianalisis sifat fisik meliputi uji organoleptik uji homogenitas, uji pH, uji daya sebar, uji daya lekat dan cycling test [13].

\subsection{Cycling Test}

Salah satu cara mempercepat evaluasi kestabilan adalah dengan cycling test. Cycling test ini dilakukan sebanyak 6 siklus, sediaan gel disimpan pada suhu dingin $\pm 4^{\circ} \mathrm{C}$ selama 24 jam lalu dikeluarkan dan ditempatkan pada suhu $\pm 40^{\circ} \mathrm{C}$, proses ini dihitung 1 siklus [14]. Parameter yang digunakan pada cycling test ini yaitu organoleptik, homogenitas, $\mathrm{pH}$, daya lekat dan daya sebar sediaan gel.

\subsection{Analisis Data}

Data dari setiap evaluasi tersebut dianalisa dengan menggunakan One Way Anova dengan program SPSS for windows.

\section{HASIL DAN PEMBAHASAN}

\subsection{Hasil Ekstraksi}

Berdasarkan hasil ekstraksi yang diperoleh dari $500 \mathrm{~g}$ serbuk daun pala dengan memakai metode maserasi menggunakan pelarut etanol 96\% diperoleh ekstrak kental dengan berat 95.889 gram sehingga persen rendemen yang dihasilkan adalah 19.17\%.

\subsection{Cycling Test}

Cycling test biasa ditujukan untuk meguji terjadinya sinersis pada gel. Sinersis terjadi karena sebagian cairan antar sel keluar kepermukaan dan menyebabkan gel mengkerut. Pengujian ini 
dilakukan dalan interval waktu sebanyak 6 siklus pada suhu tertentu, yang biasanya lebih ekstrim dari kondisi penyimpanan normal [15].

\subsubsection{Evaluasi Organoleptik dan Homogenitas Metode Cycling Test}

Ekstrak etanol daun pala diformulasikan ke dalam bentuk sediaan gel hand sanitizer dengan variasi konsentrasi HPMC dan gliserin. Penggunaan zat tambahan ini berdasarkan parameter standar umum, konsentrasi HPMC yang digunakan sebagai gelling agent adalah $2 \%-20 \%$, sedangkan konsentrasi gliserin sebagai humektan adalah $\leq 30 \%$. Data hasil pengamatan organoleptik dan homogenitas sediaan gel hand sanitizer ekstrak etanol daun pala selama cycling test dapat dilihat pada Tabel 4 .

Tabel 2. Hasil Evaluasi Organoleptik dan Homogenitas Sediaan

\begin{tabular}{ccccc}
\hline \multirow{4}{*}{ Sediaan } & \multicolumn{4}{c}{ Pengamatan } \\
\cline { 2 - 5 } & Warna & Bau & Konsistensi & Homogenitas \\
\hline F1 & Merah & Khas pala & Kental & Homogen \\
& kecoklatan & & lunak & \\
F2 & Merah & Khas pala & Kental & Homogen \\
& kecoklatan & & lunak & \\
F3 & Merah & Khas pala & Kental & Homogen \\
& kecoklatan & & & \\
\hline
\end{tabular}

Berdasarkan tabel diatas, hasil evaluasi organoleptik pada semua formula sediaan gel hand sanitizer menunjukan bahwa penyimpanan pada suhu yang berbeda-beda yang dilakukan selama 6 siklus tidak mengalami perubahan warna bau dan bentuk dari sediaan. Hasil evaluasi homogenitas terhadap semua formula menunjukan hasil yang homogen, sehingga dapat dikatakan bahwa komponen dalam ketiga formula terdispersi secara merata dan stabil baik sebelum maupun setelah pengujian.

\subsubsection{Evaluasi pH Metode Cycling Test}

Pengujian $\mathrm{pH}$ dilakukan dengan menggunakan $\mathrm{pH}$ meter. Kestabilan $\mathrm{pH}$ merupakan salah satu parameter penting yang menentukan stabil atau tidaknya suatu sediaan. Pengujian $\mathrm{pH}$ juga bertujuan untuk mengetahui tingkat keasaman sediaan saat diaplikasikan agar tidak mengiritasi kulit. Pada evaluasi stabilitas terhadap nilai $\mathrm{pH}$ sediaan menghasilkan bahwa selama pengujian cycling test, ketiga formula pada suhu $4^{\circ} \mathrm{C}$ dan $40^{\circ} \mathrm{C}$ cenderung menghasilkan nilai $\mathrm{pH}$ yang berubahubah, yaitu terjadi penurunan dan kenaikan yang bervariasi selama pengujian. Hasil yang diperoleh diketahui bahwa nilai $\mathrm{pH}$ sediaan gel hand sanitizer ekstrak daun pala dalam rentang 5.8-6.2. nilai $\mathrm{pH}$ tersebut memenuhi standar SNI No. 06-2588 dimana $\mathrm{pH}$ sediaan topikal yang aman digunakan pada kulit yaitu 4.5-6.5 [16]. Hasil pengukuran pH sediaan selama uji cycling test dapat dilihat pada Gambar 1 dan Gambar 2.

Berdasarkan hasil statistik uji normalitas (Shapiro-Wilk) dan uji homogenitas (Uji Levene) menunjukan bahwa nilai data berdistribusi normal dan homogen karena nilai signifikansinya ( $p$ value $>0.05$ ). Selanjutnya dilakukan uji One-Way ANOVA menunjukan hasil ( $p$-value $>0.05$ ), hal ini menunjukan bahwa tidak ada perbedaan bermakna dari hasil evaluasi $\mathrm{pH}$ antar formula. 


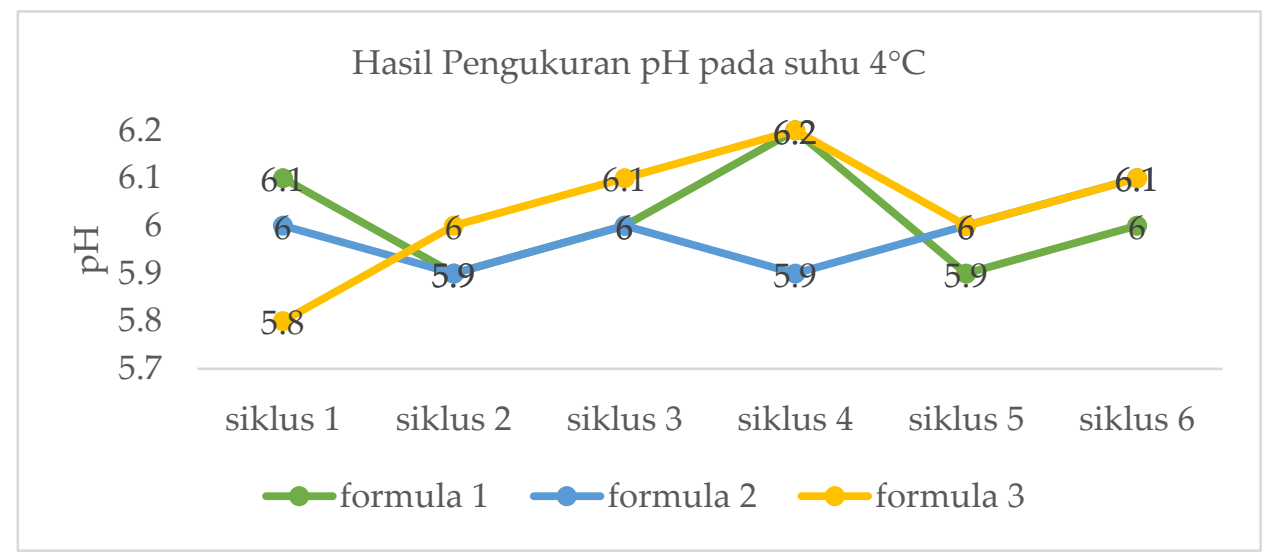

Gambar 1. Hasil Pengukuran $\mathrm{pH}$ pada Suhu $4^{\circ} \mathrm{C}$

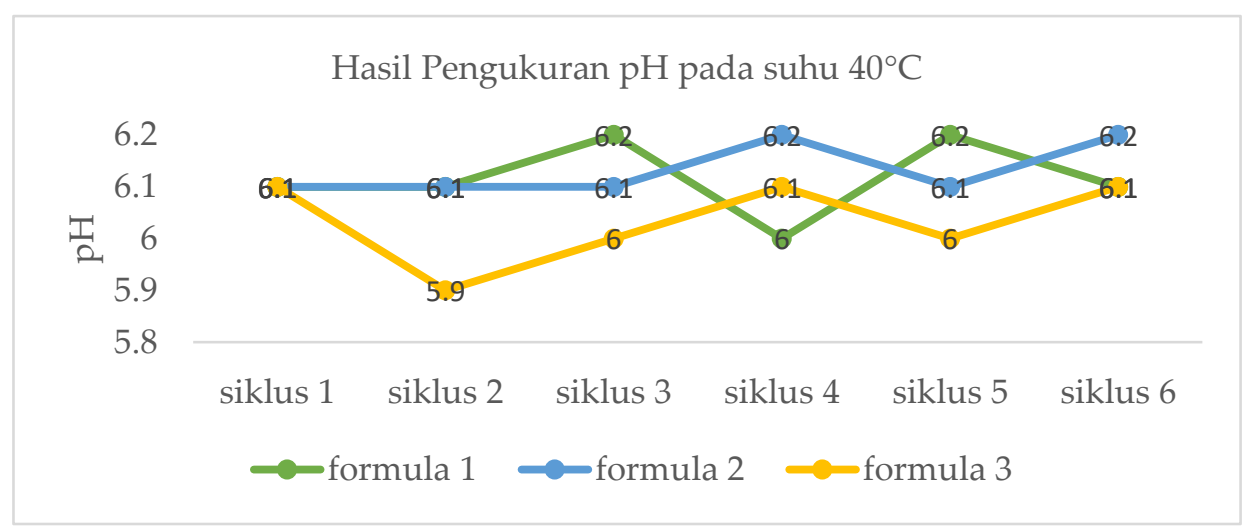

Gambar 2. Hasil Pengukuran $\mathrm{pH}$ pada Suhu $40^{\circ} \mathrm{C}$

\subsubsection{Evaluasi Daya Lekat Metode Cycling Test}

Hasil pengujian daya lekat sediaan pada suhu $4^{\circ} \mathrm{C}$ dan $40^{\circ} \mathrm{C}$ dapat dilihat pada Gambar 3 dan gambar 4 .

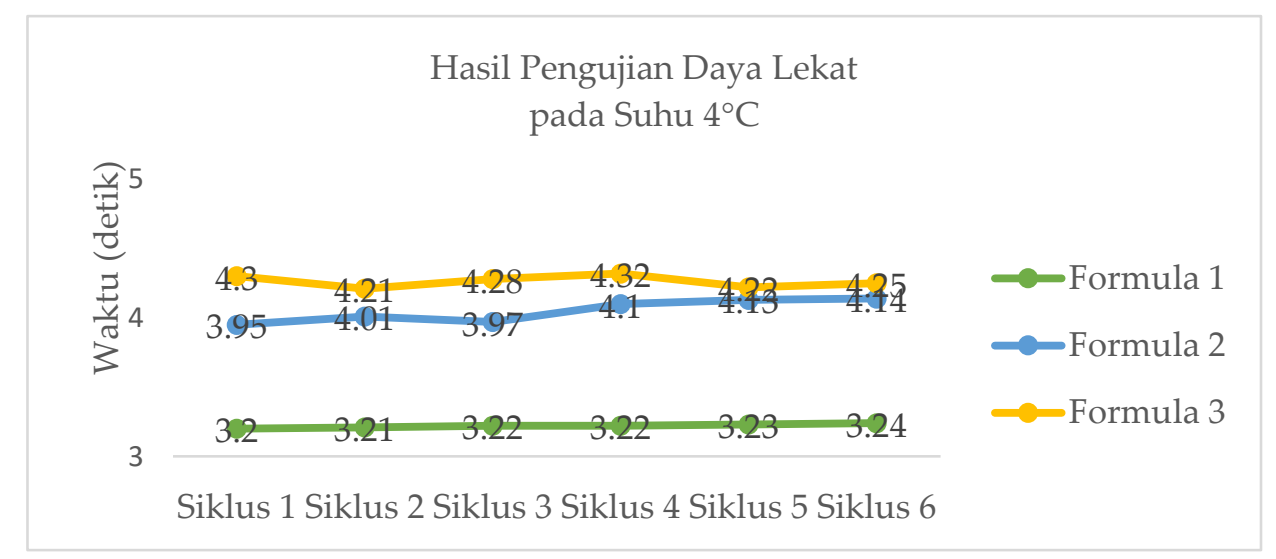

Gambar 3. Hasil Pengujian Daya Lekat pada Suhu $4^{\circ} \mathrm{C}$ 


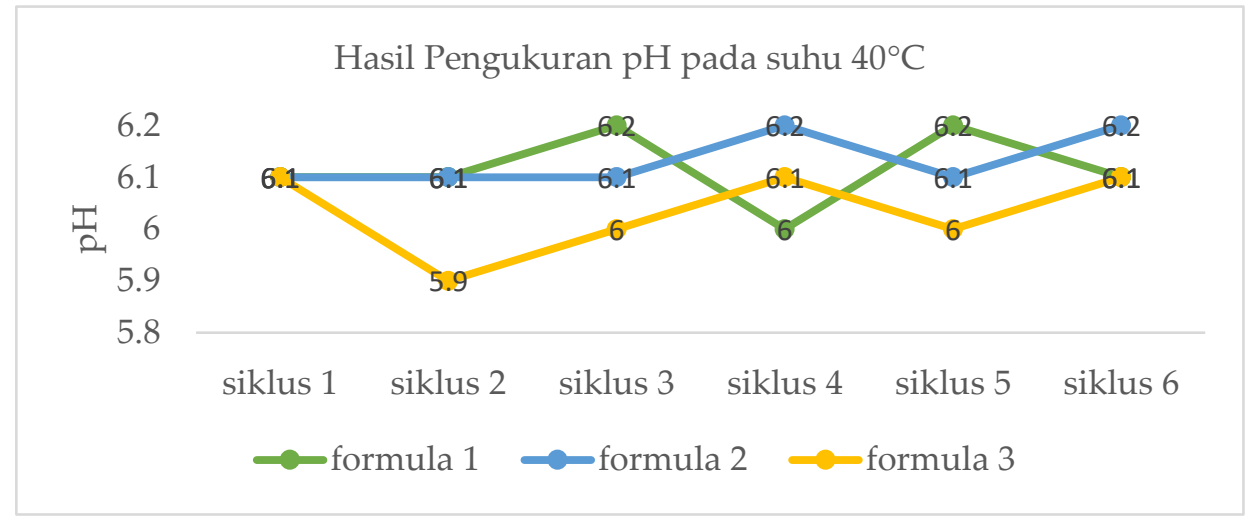

Gambar 4. Hasil Pengujian Daya Lekat pada Suhu $40^{\circ} \mathrm{C}$

Berdasarkan hasil yang diperoleh bahwa seluruh formula gel hand sanitizer ekstrak etanol daun pala selama cycling test menghasilkan nilai daya lekat yang bervariasi. Semua formula pada suhu $4^{\circ} \mathrm{C}$ cenderung menghasilkan daya lekat yang tinggi dibanding dengan formula pada pengujian suhu $40^{\circ} \mathrm{C}$ yang menghasilkan daya lekat lebih rendah, hal ini disebabkan karena semakin tinggi suhu maka sediaan gel akan melunak sehingga kemampuan untuk melekat juga menjadi menurun. Selain itu, daya lekat yang dihasilkan bervariasi juga disebabkan oleh penggunaan HPMC dan gliserin yang tinggi. Semakin tinggi gelling agent yang digunakan maka menyebabkan daya lekat semakin besar, begitu juga sebaliknya.

Berdasarkan hasil statistik menunjukan bahwa nilai data berdistribusi normal dan homogen karena nilai signifikansinya ( $p$-value $>0.05$ ). Selanjutnya dilakukan uji One-Way ANOVA menunjukan hasil ( $p$-value $<0.05$ ), hal ini menunjukan bahwa terdapat perbedaan bermakna dari hasil uji daya lekat.

\subsubsection{Evaluasi Daya Sebar Metode Cycling Test}

Hasil pengujian daya sebar sediaan pada suhu $4^{\circ} \mathrm{C}$ dan $40^{\circ} \mathrm{C}$ dapat dilihat pada Gambar 5 dan Gambar 6.

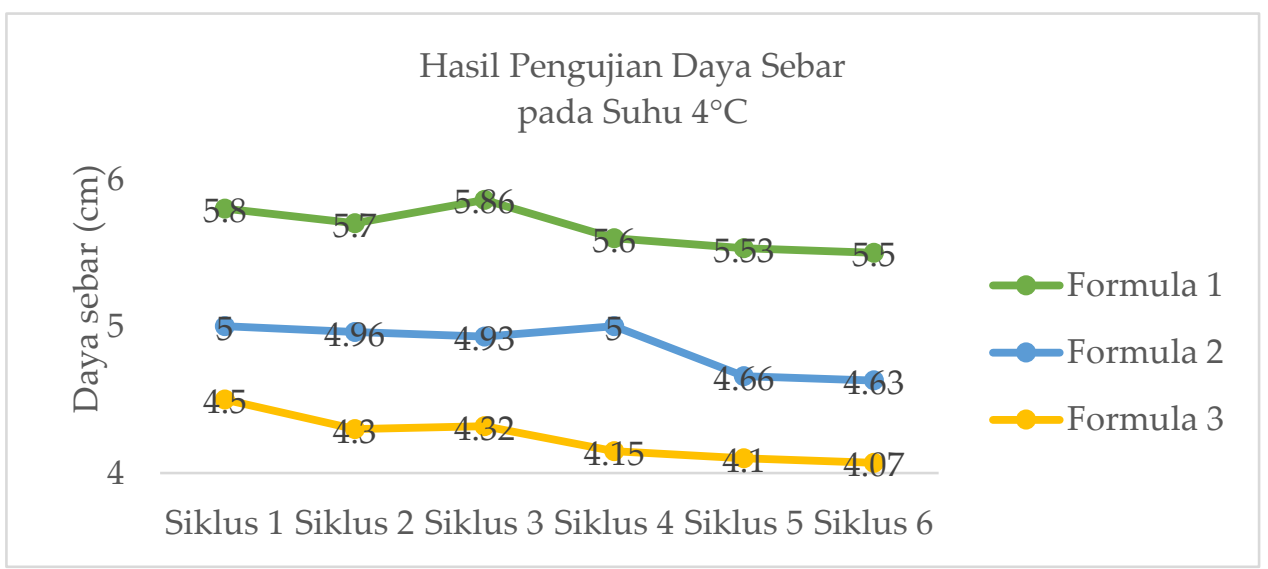

Gambar 5. Hasil Pengujian Daya Sebar pada Suhu $4^{\circ} \mathrm{C}$ 


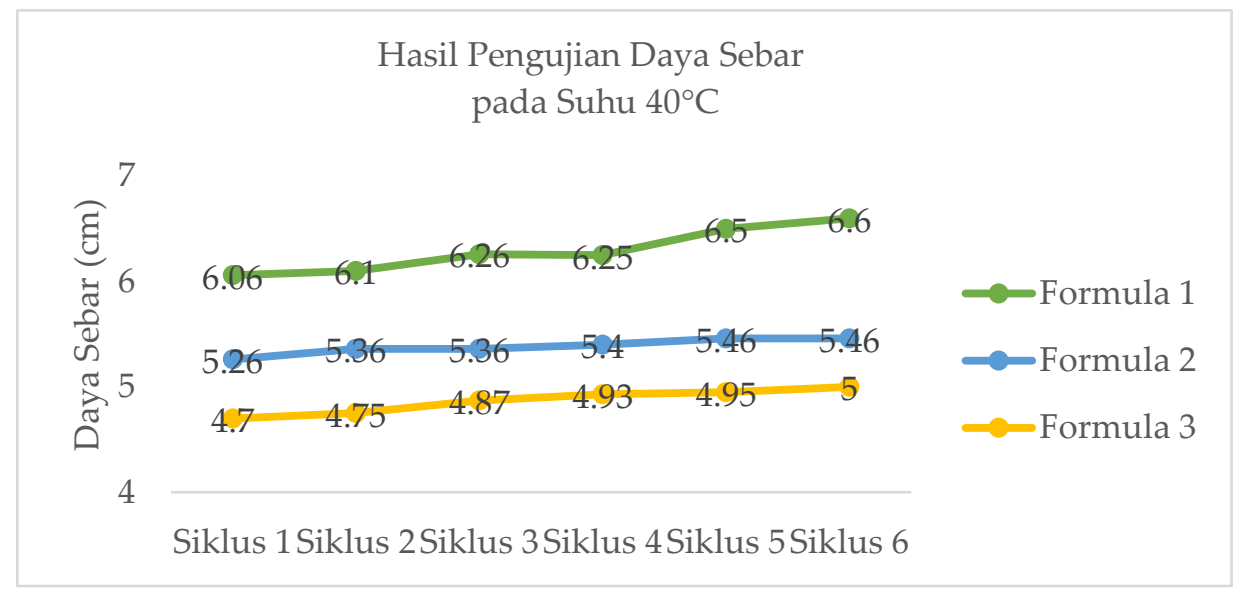

Gambar 6. Hasil Pengujian Daya Sebar pada Suhu $40^{\circ} \mathrm{C}$

Pengujian daya sebar dilakukan untuk mengetahui kemapuan gel menyebar pada permukaan kulit ketika diaplikasikan. Hasil yang diperoleh menunjukan bahwa semua formula setelah disimpan pada suhu $4^{\circ} \mathrm{C}$ dan $40^{\circ} \mathrm{C}$ menunjukan bahwa adanya penurunan dan kenaikan nilai daya sebar yang bervariasi. Penurunan daya sebar terjadi melalui meningkatnya ukuran unit molekul karena telah mengabsorbsi pelarut sehingga cairan tersebut tertahan dan meningkatkan tahanan untuk mengalir dan menyebar [17]. Selain itu, faktor yang mempengaruhi kenaikan daya sebar yaitu suhu yang tinggi dapat menyebabkan gel menyerap uap air dari luar dan menambah volume air dalam gel. Daya sebar yang baik memiliki rentang 5-7 cm [18]. Maka berdasarkan hasil pengujian daya sebar pada pada suhu $4^{\circ} \mathrm{C}$ maupun $40^{\circ} \mathrm{C}$ dapat disimpulkan bahwa semua sediaan sudah memenuhi syarat daya sebar yang baik.

Berdasarkan hasil statistik menunjukan bahwa nilai data berdistribusi normal dan homogen karena nilai signifikansinya ( $p$-value $>0.05$ ). Selanjutnya dilakukan uji One-Way ANOVA menunjukan nilai hasil ( $p$-value $<0.05)$, hal ini menunjukan bahwa terdapat perbedaan bermakna dari hasil evaluasi daya sebar.

\section{KESIMPULAN}

Formula optimum gel hand sanitizer ekstrak etanol daun pala (Myristica fragrans Houtt.) yang memiliki stabilitas paling baik adalah formula 1 dengan variasi konsentrasi HPMC 1\% dan gliserin $5 \%$.

Ucapan Terima Kasih: Terimakasih untuk Laboratorium farmasi Universitas Perjuangan Tasikmalaya yang telah memfasilitasi pelaksanaan penelitian ini.

\section{References}

1. Ismail, Isriany. Formulasi Kosmetik (Produk Perawatan Kulit dan Rambut). Makassar: Alauddin University Press. 2013.

2. Permatasari, V.S. Pengaruh Konsentrasi Carbopol 940 Sebagai Gelling Agent Terhadap Sifat Fisis dan Stabilitas Gel Hand Sanitizer Minyak Daun Mint (Oleum Mentha Piperita). Universitas Sanata Dharma. Jakarta. 2014.

3. Hariana, A. Tumbuhan Obat \& Khasiatnya. Penebar Swadaya. Jakarta. 2013. Hal 264.

4. Rizal, Y.M. Uji Aktivitas Antibakteri Ekstrak Etanol Daun Pala (Myristica fragrans Houtt.) Terhadap Staphylococcus aureus dan Escherichia coli. Universitas Sumatera Utara. Medan. 2016. 
5. Octavia, Nurlina. Formulasi Sediaan Gel Hand Sanitizer Minyak Atsiri Pala (Mysristica fragrans Houtt): Uji Stabilitas Fisik dan Uji Aktivitas Antibakteri Terhadap Bakteri Staphylococcus aureus. Universitas Muhammadiyah Surakarta.2016.

6. Anggraini, Ovi. Uji Aktivitas Anti Bakteri Sediaan Gel Hand Sanitizer Ekstrak Etanol Daun Pacar Kuku (Lawsonia inermis L.) Terhadap Bakteri Staphylococcus aureus ATCC 25923. Universitas Setia Budi. Surakarta. 2016.

7. Damayanti, A.T.R. Pengaruh Konsenrasi HPMC dan Propilenglikol Terhadap Sifat dan Stabilitas Fisik Sediaan Gel Ekstrak Pegagan (Centella asiata (L.) Urban). Universitas Sanata Dharma. Yogyakarta. 2016.

8. Setyaningrum, N.L. Pengaruh Variasi Kadar Basis HPMC dalam Sediaan Gel Ekstrak Etanolik Bunga Kembang Sepatu (Hibiscus rosa sinensis L.) Terhadap Sifat Fisika dan Daya Antibakteri pada Staphylococcus aureus. Naskah Publikasi. Fakutas Farmasi Universitas Muhammadiyah. Surakarta. 2013.

9. Nursiah, H., Faradiba, Baharuddin, G. A. Formulasi gel sari buah belimbing wuluh (Averrhoa bilimbi L.), Universitas Hasanuddin dan Universitas Muslim Indonesia Makassar, Majalah Farmasi dan Farmakologi. 2011. 15 (1) : Hal 5-9.

10. Soerarti, W., Rasita, N., dan Himawati, E. R. Pengaruh Jenis Humektan Terhadap Pelepasan Asam Sitrat Dari Basis Gel Secara In Vitro. J. Phar. 2016. 4 (2).

11. Sayuti, N.A. Formulasi dan Uji Stabilitas Fisik Sediaan Gel Ekstrak Daun Ketepeng Cina (Cassia alata L.). Jurnal Kefarmasian Indonesia. 2015. 5(2), 10-14.

12. Marinda, W.S. Formulasi dan Uji Stabilitas Fisik Gel Liposom yang Mengandung Fraksinasi Ekstrak Methanol Kulit Manggis (Garcinia mangostana L.) Sebagai Antioksidan. Universitas Indonsia. Depok. 2012.

13. Saraung. V., Yamlean.P.V.,Citraningtyas.G. Pengaruh Variasi Basis Karbopol dan HPMC pada Formulasi Gel Ekstrak Etanol Daun Tapak Kuda (Ipomoea pes-caprae (L.) R. Br.) dan UJi Aktivitas Antibakteri Terhadap Staphylococcus aureus. Jurnal Ilmiah Farmasi. 2018. 7(3), 2302-2493.

14. Dewi, R.K. Optimasi Formulasi Mikroemulsi Sediaan Hormone Testosterone Undekanoat (Skripsi). Universitas Negeri Islam Syarif Hidayatulloh. Jakarta. 2010.

15. Angela, Lasmida. Aktivitas Antioksidan dan Stabilitas Fisik Gel Anti-Anging Yang Mengandung Ekstrak Air Kentang Kuning (Solanum tuberosum L.) [Skripsi] Depok : Universitas Indonesia. 2012.

16. Safitri.,NA, Oktavia EP, Valentina Y. Optimasi Formula Sediaan Krim Ekstrak Stroberi (Fragaria $x$ ananassa) Sebagai Krim Anti Penuaan. Majalah kesehatan FKUB. 2014. 1(4)236-245.

17. Martin, A., J, Swarbrick., and A Camarata. Farmasi Fisik : Dasar-Dasar Farmasi Fisik Dalam Ilmu Farmasetik. Edisi Ketiga. Penerjemah: Yoshita. Jakarta: UI Press. 1993.

18. Adnan,J. Formulasi Gel Ekstrak Daun Beluntas (Pluceaindicaless) dengan Na-CMC Sebagai Basis Gel. Journal of pharmaceutical science and herbal technology. 2016.1 (1), 41-44.

(C) 2021 by the authors. Submitted for possible open access publication under the terms and conditions of the Creative Commons Attribution (CC BY) license (http://creativecommons.org/licenses/by/4.0/). 